\title{
Implementing social interventions in primary care
}

\author{
Gary Bloch MD, Linda Rozmovits DPhil
}

- Cite as: CMAJ 2021 November 8;193:E1696-1701. doi: 10.1503/cmaj.210229

M

ost family physicians now report that they engage in some degree of social intervention in the management of patients. ${ }^{1}$ However, outside of community health centres, social interventions are still not a routine part of primary care practice and are not yet considered "standard of care." Traditional primary care seldom included interventions such as social prescribing and health-legal partnerships until the early $1990 \mathrm{~s},{ }^{2}$ and some practitioners still question whether social intervention is part of the primary care provider's role. ${ }^{3}$ A small cadre of practitioners in high-income countries, including Canada, Australia, the United Kingdom and the United States, has been at the forefront of developing and evaluating interventions into social risks to health, which has led to a few social interventions being widely adopted, with positive impacts on broad markers of health.

Producing high-quality, clinically actionable research on social interventions in primary care is challenging. The effects of living with social pressures such as poverty, racism or trauma are difficult to evaluate over the duration of a typical study using traditional markers of change in physical or mental health. For this reason, the literature on social interventions in primary care often focuses on process rather than outcome measures, and on self-reported indicators of health and well-being. ${ }^{31}$ Despite these limitations, the literature points to a positive general impact on health of social interventions.

\section{Box 1: Evidence used in this review}

In October 2018, we conducted an extensive, nonsystematic review of the literature with the aid of a medical librarian, which we updated in November 2020. We searched MEDLINE, Embase, CINAHL and Sociological Abstracts. Search terms, which varied slightly by database, included "* primary health care/or patient-centered care," "primary care," "physicians, family," "general pract*," "family pract*," "family physician*," "social determinants of health," "social equit*," "social screening," "social prescribing," "social determinant" and "social barrier"." We limited the search to English language articles. We identified grey literature through discussion with experts, scanning reference lists and Google searches. In an attempt to maintain a focus on interventions replicable across practice settings, we limited our search to high-income countries. This search yielded 895 unique abstracts, which we both reviewed for relevance. We selected 177 articles for full review.

\section{Key points}

- Primary care-based social interventions offer an important means to mitigate threats to individual and community health posed by adverse social conditions.

- Effective interventions include those that target individual-level determinants, connections with community resources, community-focused partnerships and structures within health teams that affect equity.

- Accumulating evidence points to the positive impacts of social interventions on broad markers of health; however, most research in this area has focused on implementation and process measures, rather than outcomes.

- Some interventions require large, interdisciplinary health care resources to implement, but many are accessible to small group practices or individual providers.

We discuss accumulated evidence (Box 1) on social interventions and provide an overview of common primary care-based interventions (Table 1), highlighting their strengths, limitations and feasibility of implementation in different practice settings. We discuss levels of practice resources that would facilitate their implementation, and also suggest those interventions that could be led by an external community partner, which may provide an alternate avenue for less well-resourced practices. Although the incorporation of new interventions may seem daunting, especially to community-based health care providers without an interdisciplinary team, we have been involved in change processes with practices of all sizes to incorporate social interventions.

\section{How can patients' social needs be identified?}

The first step in addressing social risk factors for poor health is to identify an individual's needs in relation to social factors that may be affecting their health, such as income, housing, literacy, education and employment, or socially defining life experiences, such as trauma, racism, homophobia or domestic violence. Questions related to social needs also enable identification of individual and community assets that could be leveraged in building a program of care, such as support networks or neighbourhood associations. 


\begin{tabular}{|c|c|c|c|c|c|}
\hline Intervention & Infrastructure required & $\begin{array}{c}\text { Solo } \\
\text { practitioner }\end{array}$ & $\begin{array}{l}\text { Small } \\
\text { group }\end{array}$ & $\begin{array}{l}\text { Large } \\
\text { interdisciplinary } \\
\text { group }\end{array}$ & $\begin{array}{l}\text { Community } \\
\text { partner }\end{array}$ \\
\hline Social needs screening & Front-line provider or support staff willing to engage & $x$ & $x$ & $x$ & \\
\hline Literacy & $\begin{array}{l}\text { Front-line providers willing to engage; financial } \\
\text { resources to purchase books }\end{array}$ & $x$ & $x$ & $x$ & \\
\hline $\begin{array}{l}\text { Income security } \\
\text { specialists }\end{array}$ & $\begin{array}{l}\text { Social needs screening, and funded in-team income security } \\
\text { specialist or partnership with outside specialized agency }\end{array}$ & & $x$ & $x$ & $x$ \\
\hline Social prescribing & $\begin{array}{l}\text { Social needs screening, link worker (funded by practice } \\
\text { or partnership with external organization), and practice } \\
\text { lead to coordinate and supervise }\end{array}$ & & $\mathrm{x}$ & $\mathrm{x}$ & $x$ \\
\hline $\begin{array}{l}\text { Equity-oriented } \\
\text { practice change }\end{array}$ & $\begin{array}{l}\text { Front-line providers and team members willing to } \\
\text { explore structural inequities, and engage in team } \\
\text { training and ongoing discussion; external consultant or } \\
\text { guide to facilitate practice exploration and change }\end{array}$ & & $x$ & $x$ & \\
\hline $\begin{array}{l}\text { Health-legal } \\
\text { partnership }\end{array}$ & $\begin{array}{l}\text { Legal needs screening and partnership with legal agency; } \\
\text { office and supplies for legal staff; practice lead to coordinate }\end{array}$ & & & $x$ & $\mathrm{x}$ \\
\hline Social data collection & $\begin{array}{l}\text { Access to data (in electronic health record or external } \\
\text { database); data processing and analysis expert }\end{array}$ & & & $\mathrm{x}$ & $\mathrm{x}$ \\
\hline $\begin{array}{l}\text { Community partnership } \\
\text { or community } \\
\text { development }\end{array}$ & $\begin{array}{l}\text { Front-line providers and team leadership willing to engage } \\
\text { in community meetings and adjust team infrastructure; } \\
\text { specialized community health or development workers }\end{array}$ & & & $x$ & $x$ \\
\hline
\end{tabular}

\section{Screening tools}

Routinely recording a patient's social pressures at health visits enables providers to adjust assessments of need and to determine the resources required to address them. Social needs screening is also often a prerequisite to patients accessing benefit programs and the services of community-based organizations.

Currently available tools range from those that support targeted screening approaches for single determinants, such as income or adverse childhood experiences, to those that provide a more comprehensive assessment of social need. The Clinical Tool on Poverty offers a single question screen for income security: "Do you ever have trouble making ends meet at the end of the month?" Simple to use, this question has a sensitivity of $98 \%$ and a specificity of $40 \%$ for identifying people living below the poverty line. ${ }^{4,5}$ More comprehensive social needs screening tools, such as HealthBegins and the Protocol for Responding to and Assessing Patients' Assets, Risks and Experiences (PRAPARE), explore multiple domains of social risk that range from housing to childcare to neighbourhood safety. ${ }^{6}$ Evaluation of multifaceted tools has shown that many individuals have multiple, intersecting social needs. ${ }^{7}$ The Siren Network has published a comparison table of social screening tools used in the US. ${ }^{8}$

Implementation of screening requires training and buy-in from front-line health providers. It also requires sustained commitment and the allocation of time and resources. ${ }^{9-11}$ However, neither the training nor the resource demands are onerous. Some screening tools can be implemented by office staff or by using electronic interfaces, such as tablets handed to patients for selfcompletion of simple questionnaires. ${ }^{12,13}$

\section{Local research}

Although the focus of clinical screening tools is the identification of individual need, practice- and population-level data can enable higher-level efforts to engage in social interventions. Data from electronic health records can be used to build a picture of social need within a practice population ${ }^{14}$ and to guide quality improvement initiatives. ${ }^{15}$ As such, social needs screening can form a foundation for further action on social risks to health and inform the design, monitoring and evaluation of interventions.

The HealtheRx project in Chicago and the Ontario Health Profiles website translate community-level social data for the use of health teams and other social services. ${ }^{16,17}$ The University of Toronto Practice-Based Research Network (UTOPIAN) project allows researchers to access anonymized data from electronic health records from 1700 family physicians. ${ }^{18}$ Large databases are also being used to incorporate social data into predictive, artificial intelligence algorithms to identify and target services to high-needs individuals and groups. ${ }^{19,20}$

Identifying people with higher social and health needs and, by extension, higher health system costs can be harmful if those data are used to restrict services. ${ }^{21,22}$ Moreover, the identification of social needs does not always translate into uptake of social interventions, which may point to a disconnect between identification and ability to address need. ${ }^{23}$

\section{How can physicians connect patients with effective social supports?}

Social prescribing leverages individual and community assets with a view to improving individual well-being, self-management and empowerment. ${ }^{24,25}$ As such, it uses a structured approach to refer 
patients to community supports. Along with a focus on lifestyle factors, such as exercise, many social prescribing programs seek to directly address social determinants, such as income and housing.

Social prescribing typically requires a health professional to make a referral to a community resource and engagement specialist, known as a link worker. The link worker meets with clients to explore their circumstances and codetermine their needs, then connects clients to appropriate local services, accompanying them and supporting them through their journey as required. Link workers may be embedded in primary care practices or based in the community. They provide expertise, capacity and sustained support in a way that is seldom possible for primary care providers.

Social prescribing is widely implemented in the UK, now supported by the National Health Service; its Social Prescribing Network organizes practices nationally and regionally. ${ }^{26}$ In the US, the Health Leads program relies on volunteer university students to facilitate links to support programs ${ }^{27}$ In Canada, the Alliance for Healthier Communities recently completed a pilot program to build community-designed social prescribing programs into community health centres. ${ }^{24}$ In Winnipeg, the government-funded model, My Health Team, supplies multidisciplinary health providers, including income specialists and community navigators, to small group and solo family practices. Services are mobilized by primary care providers through an electronic medical recordintegrated interface that facilitates team communication. ${ }^{28,29}$ In the absence of such external support, social prescribing requires financial and human resources, and is most easily implemented by a well-resourced interdisciplinary team. ${ }^{30}$

Social prescribing has shown promising outcomes, including improvements in broad markers of health and well-being. ${ }^{32-35}$ Research from the UK has reported improved resilience, mental health, quality of life and successful modification of lifestyle factors, as well as stronger links between health and communitybased services, a reduction in drug prescribing, an increase in preventive management and a reduction in primary care use by patients seeking help for unmet social needs. ${ }^{25} \mathrm{~A}$ strong case management role for link workers has been associated with improved outcomes and health team satisfaction. ${ }^{36}$

\section{How can individual social determinants of health be addressed directly?}

\section{Income security}

Primary care-based programs for income intervention have emerged in some settings over the last 30 years and largely focus on helping low-income individuals access benefits, consolidate and reduce debt, and increase their financial literacy.

Services offering advice on welfare rights have been implemented across the UK since the mid-1990s. Often colocated with health teams, they focus on maximizing client access to social assistance supports. Evaluations have shown that service access is associated with an improvement in income, as well as in indices of well-being. ${ }^{37}$

In Canada, income specialists are embedded in several primary care teams. They focus on individual income security assessments, as well as health provider education and social policy advocacy.
Early implementation analyses and administrative data are promising, but the results of outcomes studies, including a randomized controlled trial, have not yet been released..$^{38}$

Other promising approaches include peer-led financial coaching, partnerships between medical and financial agencies, and the colocation of tax return services at clinical sites. Evaluations have shown a positive impact on well-being, as well as a strong return on investment. ${ }^{39-41}$

The establishment of income support programs requires funding for embedded specialists or partnership with community organizations that have the expertise and capacity to carry out this work. Practices with fewer resources can establish and maintain lists of income benefits programs and local, free tax clinics to which patients may be referred.

\section{Legal needs}

Programs that offer legal services directly to clients of health teams first emerged in the US in 1993. By 2010, more than 200 American hospitals and community health centres were engaged in such partnerships. ${ }^{42}$ Health-legal partnerships have now also emerged in Canada, the UK and Australia. ${ }^{43}$

Legal providers may be embedded directly in primary care teams, colocated or accessed through a referral process. In addition to providing legal assistance to individual clients, they may engage in health provider and client education and advocacy for systemic change through law reform. They are supported by government or private funding, and through partnerships with private and public legal service organizations. ${ }^{42}$

A high-functioning health-legal partnership in Cincinnati, Child HeLP, paired a pediatric primary care service with a legal community agency with expertise in serving populations that are socially marginalized. An evaluation of the program showed positive legal outcomes, focused heavily on income and housing concerns for children with chronic illness. ${ }^{44}$

Implementation and outcome studies of health-legal partnerships point to a feasible, high-impact model with strong potential for improving health outcomes. ${ }^{45}$ However, they require substantial health team, legal and community partnership resources, and are most easily implemented in larger team settings or with strong community partner or government support.

\section{Literacy}

Literacy is a marker of educational attainment, and low education may be associated with poverty. Literacy is also often a prerequisite for accessing employment and navigating health and social supports. The American Academy of Pediatrics, among other organizations, promotes literacy awareness as an essential part of primary care practice. ${ }^{46}$

A health-based literacy intervention, Reach Out and Read, was created in Boston in 1989, and has been implemented in more than 6400 sites in North America. It trains health practitioners to provide literacy counselling, free books and referral to literacy organizations to families with young children. Evaluations show positive literacy outcomes, with a particularly strong impact on children from low-income families. ${ }^{47}$ 
This intervention can be established in practices with limited resources. It requires some initial training and sponsorship for books, but ultimately relies on front-line providers devoting a few minutes to discussing literacy with parents at child health visits.

\section{Social isolation}

Social isolation and loneliness have been shown to be risk factors for poor health and increased risk of death, especially among people older than 50 years. ${ }^{48}$ The prevalence and health impacts of social isolation are magnified among people living at low incomes or without adequate housing. ${ }^{49}$

Interventions may tackle social isolation from many angles, including improving mobility and hearing, building social skills, reducing lack of access to transportation, and addressing cognitive and psychological challenges through targeted psychotherapy. Evidence is mostly of low quality, with the greatest impact to date associated with interventions that increase physical activity. ${ }^{50}$

\section{Employment, housing, transportation and food security}

The evidence base for other primary care-based, individualfocused, social interventions is growing, but remains relatively sparse. A systematic review found few primary care-based interventions that targeted employment, with most focused on patients with severe mental illness. It did, however, point to the potential for embedded employment specialists or partnerships with community agencies to improve employment outcomes for patients. ${ }^{51}$ Housing interventions, although impactful, have almost exclusively been studied in specialized health care settings that provide services to people experiencing homelessness..$^{52}$ Transportation to medical appointments has been identified as a determinant of access to care, and interventions may enable clients to connect with health care services. ${ }^{53}$ Food insecurity is often screened for in primary care, but since food insecurity is a proxy for inadequate income, the utility of interventions that are limited to food provision are questionable. ${ }^{54-56}$

\section{How can health providers engage with communities to address social needs?}

Targeting social determinants in communities rather than for the individual, through community-collaborative, primary carebased interventions, also offers strong potential to expand the integration and impact of primary health care teams. ${ }^{57}$

The Keeping Infants Nourished and Developing (KIND) program in Cincinnati leveraged a strong community partnership to address food insecurity and other social needs for children living in poverty. ${ }^{54} \mathrm{~A}$ review of the evidence showed a positive return on investment for health-community partnerships focused on housing, nutrition, transportation, home modification and navigation of health and social care. ${ }^{58}$

Specialized community health workers, who are often also community members, contribute local knowledge to health teams. In addition to identifying social needs, they can lead outreach and engagement for health teams, with a focus on health education, care coordination and health literacy. A program at the Mayo Clinic placed community health workers in practices under the cosupervision of health teams and community groups. The workers were often from similar socioeconomic and cultural backgrounds to clients and helped individual patients navigate health and social needs. The program resulted in decreased outpatient visits, emergency department use and health costs. ${ }^{59}$

A community development model takes this approach one step further by focusing on organization, empowerment and community leadership of program development. Specialized community development workers lead community members in identifying needs and leveraging local and external assets to develop programs to address those needs. One group in the UK estimated a $380 \%$ return on investment for their health-focused community development initiative. ${ }^{60}$ Encouragement of democratic engagement by health care providers may support marginalized communities to increase their impact on community structures and social policy. ${ }^{61}$

A community focus requires deep involvement with, and assessment of, community needs, and support for communityled efforts to address those needs. Community-focused interventions are most easily implemented by larger interdisciplinary teams. Any practitioner, however, can begin to forge partnerships with community agencies. In the US, the Health Extension program provided 1500 small primary care practices with government funding to hire workers to engage with community needs, modelling how a large funder can empower small health practices to deepen their community ties. ${ }^{62}$

\section{How can health teams actively address structural drivers of inequity within their services?}

An emerging area of inquiry evaluates drivers of inequity, such as racism and colonialism, and how they manifest in the operations of health teams. Those involved in addressing these determinants of health look to techniques such as cultural safety, critical reflection and antioppressive approaches to help providers understand how inequities manifest throughout health care interactions, as well as through the core structures of our society. ${ }^{63}$

In Vancouver, the EQUIP project explored the effects of an intervention on the structural determinants of health in $5 \mathrm{com}$ munity health centres that serve socially marginalized populations in western Canada. The intervention reported perceived improvement in the ability of staff to recognize inequity and to address the needs of clients facing complex medical and social issues. ${ }^{64} \mathrm{~A}$ subsequent evaluation showed that patients reported improved health outcomes postintervention. ${ }^{65}$

A Canada-wide initative on Indigenous cultural safety has offered Web-based training to thousands of health care providers. ${ }^{66}$ Its impact is currently being studied in a primary care setting. ${ }^{67}$

Health team engagement with equity-oriented practice change requires resources to hire embedded equity specialists or to engage external expertise to guide the process. It also requires willingness to tackle subjects that are often personally uncomfortable, such as individual and social group privilege. 


\section{What are the challenges?}

Despite the encouraging evidence presented herein, barriers to implementation of social prescribing remain. Conventional approaches to health program evaluation are, arguably, ill-suited to assessing the effects of interventions that are expected to produce improvements in health over many years. In addition, practitioners are understandably concerned about the time and resources these interventions require, both to initiate and to maintain. ${ }^{68}$ However, recent research has suggested that engagement with social needs reduces physician burnout, and improves job satisfaction and perceived quality of care. ${ }^{69-71}$ Moreover, the important contribution of social conditions in determining health dictates the imperative to act to address these conditions. This is an emerging area of practice and health providers, researchers and health program designers share responsibility for the continued establishment and evaluation of social interventions.

Health-harming social factors, such as economic inequality, misogyny, homophobia, systemic racism and colonialism, require action beyond the medical office, and some stakeholders caution that attempting to address social needs through medical care may misdirect resources and responsibility away from the need to advance policy and dismantle harmful societal structures. ${ }^{72,73}$

\section{Conclusion}

Interventions to improve the social situation of patients in primary care can lead to improvements in health and sensitize providers to their responsibility to address health-harming social conditions. Any primary care provider can engage in some degree of social intervention. The extent and success of these interventions will depend on a desire to prioritize them, dedicate resources, and engage with community partners and interdisciplinary supports. Social interventions offer an important step toward offering more holistic primary care.

\section{References}

1. Kovach KA, Reid K, Grandmont J, et al. How engaged are family physicians in addressing the social determinants of health? A survey supporting the American Academy of Family Physician's health equity environmental scan. Health Equity 2019;3:449-57.

2. Russell G, Dahrouge S, Tuna M, et al. Getting it all done. Organizational factors linked with comprehensive primary care. Fam Pract 2010;27:535-41.

3. Solberg LI. Theory vs practice: should primary care practice take on social determinants of health now? No. Ann Fam Med 2016;14:102-3.

4. Poverty: a clinical tool for primary care providers. Toronto: Centre for Effective Practice (CEP); 2016. Available: https://cep.health/clinical-products/poverty-a -clinical-tool-for-primary-care-providers/\#pc_page_44 (accessed 2021 Jan. 28).

5. Brcic V, Eberdt C, Kaczorowski J. Corrigendum to "Development of a tool to identify poverty in a family practice setting: a pilot study". Int J Family Med 2015;2015:418125.

6. Center for Youth Wellness ACEQ \& User Guide. San Francisco: Center for Youth Wellness; 2017. Available: https://centerforyouthwellness.org/cyw-aceq/ (accessed 2021 Jan. 28).

7. Weir RC, Proser M, Jester M, et al. Collecting social determinants of health data in the clinical setting: findings from national PRAPARE implementation. $J$ Health Care Poor Underserved 2020;31:1018-35.

8. Screening tools comparison table. San Francisco: Social Interventions Research \& Evaluation Network (SIREN), University of San Francisco California. Available: https://sirenetwork.ucsf.edu/siren-resources/screening-tool-comparison-table-0 (accessed 2021 Jan. 28).

9. Andermann A. Screening for social determinants of health in clinical care: moving from the margins to the mainstream. Public Health Rev 2018;39:19.
10. Tong ST, Liaw WR, Kashiri PL, et al. Clinician experiences with screening for social needs in primary care. J Am Board Fam Med 2018;31:351-63.

11. Gottlieb L, Sandel M, Adler NE. Collecting and applying data on social determinants of health in health care settings. JAMA Intern Med 2013;173:1017-20.

12. Pinto AD, Glattstein-Young G, Mohamed A, et al. Building a foundation to reduce health inequities: routine collection of sociodemographic data in primary care. J Am Board Fam Med 2016;29:348-55.

13. Gottlieb L, Hessler D, Long D, et al. A randomized trial on screening for social determinants of health: the iScreen study. Pediatrics 2014;134:e1611-8.

14. Gold R, Cottrell E, Bunce A, et al. Developing electronic health record (EHR) strategies related to health center patients' social determinants of health. $J$ Am Board Fam Med 2017;30:428-47.

15. Lofters AK, Schuler A, Slater M, et al. Using self-reported data on the social determinants of health in primary care to identify cancer screening disparities: opportunities and challenges. BMC Fam Pract 2017;18:31.

16. Hughes LS, Phillips RL Jr, DeVoe JE, et al. Community vital signs: taking the pulse of the community while caring for patients. J Am Board Fam Med 2016;29:419-22.

17. Ontario Community Health Profiles Partnership [home page]. Available: www. ontariohealthprofiles.ca (accessed 2021 Jan. 28).

18. About UTOPIAN. Toronto: University of Toronto; 2021. Available: https://www. dfcm.utoronto.ca/about-utopian (accessed 2021 Jan. 28).

19. Kasthurirathne SN, Grannis S, Halverson PK, et al. Precision health-enabled machine learning to identify need for wraparound social services using patientand population-level data sets: algorithm development and validation. JMIR Med Inform 2020;8:e16129.

20. Chen S, Bergman D, Miller K, et al. Using applied machine learning to predict healthcare utilization based on socioeconomic determinants of care. Am J Manag Care 2020;26:26-31.

21. Gottlieb LM, Alderwick H. Integrating social and medical care: Could it worsen health and increase inequity? Ann Fam Med 2019;17:77-81.

22. Gottlieb LM, Francis DE, Beck AF. Uses and misuses of patient-and neighborhoodlevel social determinants of health data. Perm J 2018;22:18-078.

23. De Marchis EH, Alderwick H, Gottlieb LM. Do patients want help addressing social risks? J Am Board Fam Med 2020;33:170-5.

24. Rx: Community - Social prescribing in Ontario. Toronto: Alliance for Healthier Communities; 2020. Available: https://www.allianceon.org/Rx-Community -Social-Prescribing-Ontario (accessed 2021 Jan. 28).

25. Polley M, Fleming J, Anfilogoff T, et al. Making sense of social prescribing. London (UK): University of Westminister; 2017:1-79. Available: https://42b7de07-529d-4774 -b3e1-225090d531bd.filesusr.com/ugd/14f499_816dc79e160a4e77991599a74236 d0d4.pdf (accessed 2021 Jan. 28).

26. The Social Prescribing Network [home page]. Available: https://www. socialprescribingnetwork.com (accessed 2021 Jan. 28).

27. Health Leads [home page]. Available: https://healthleadsusa.org (accessed 2021 Jan. 28).

28. Hochman M, Jones A, Doering T, et al. Treating the patient who can't make ends meet. In: Family Medicine Forum; 2019 Oct. 30-Nov. 2; Vancouver. Mississauga (ON): College of Family Physicians Canada.

29. L'Esperance S. Exploring income security offered through primary care: a mixedmethods process evaluation [thesis]. Winnipeg: University of Manitoba; 2019. Available: hdl.handle.net/1993/34500 (accessed 2021 Jan. 28).

30. Whitelaw S, Thirlwall C, Morrison A, et al. Developing and implementing a social prescribing initiative in primary care: insights into the possibility of normalisation and sustainability from a UK case study. Prim Health Care Res Dev 2017;18:112-21.

31. Gottlieb LM, Wing H, Adler NE. A systematic review of interventions on patients' social and economic needs. Am J Prev Med 2017;53:719-29.

32. Brandling J, House W. Social prescribing in general practice: adding meaning to medicine. Br J Gen Pract 2009;59:454-6.

33. Bertotti $M$, Frostick $C$, Hutt $P$, et al. A realist evaluation of social prescribing: an exploration into the context and mechanisms underpinning a pathway linking primary care with the voluntary sector. Prim Health Care Res Dev 2018;19:232-45.

34. Gottlieb L, Cottrell EK, Park B, et al. Advancing social prescribing with implementation science. J Am Board Fam Med 2018;31:315-21.

35. Alderwick HAJ, Gottlieb LM, Fichtenberg CM, et al. Social prescribing in the US and England: emerging interventions to address patients' social needs. $A m \mathrm{~J}$ Prev Med 2018;54:715-8.

36. Skivington $\mathrm{K}$, Smith $\mathrm{M}$, Chng NR, et al. Delivering a primary care-based social prescribing initiative: a qualitative study of the benefits and challenges. $\mathrm{Br} J$ Gen Pract 2018;68:e487-94.

37. Adams J, White M, Moffatt S, et al. A systematic review of the health, social and financial impacts of welfare rights advice delivered in healthcare settings. $B M C$ Public Health 2006;6:81. 
38. Jones MK, Bloch G, Pinto AD. A novel income security intervention to address poverty in a primary care setting: a retrospective chart review. BMJ Open 2017;7:e014270.

39. Pinto $A D$, Da Ponte $M$, Bondy $M$, et al. Addressing financial strain through a peer-to-peer intervention in primary care. Fam Pract 2020;37:815-20.

40. Black S, Sisco S, Williams T, et al. Return on investment from co-locating tax assistance for low-income persons at clinical sites. JAMA 2020;323:1093-5.

41. Bell ON, Hole MK, Johnson K, et al. Medical-financial partnerships: cross-sector collaborations between medical and financial services to improve health. Acad Pediatr 2020;20:166-74.

42. Sandel M, Hansen M, Kahn R, et al. Medical-legal partnerships: transforming primary care by addressing the legal needs of vulnerable populations. Health Aff (Millwood) 2010;29:1697-705

43. International Medical-Legal Partnerships. Washington (DC): George Washington University. Available: https://medical-legalpartnership.org/partnerships/ international/ (accessed 2021 Jan. 28).

44. Klein MD, Beck AF, Henize AW, et al. Doctors and lawyers collaborating to HeLP children: outcomes from a successful partnership between professions. J Health Care Poor Underserved 2013;24:1063-73.

45. Murphy C. Making the case for Medical-Legal Partnerships: an updated review of the evidence, 2013-2020. Washington (DC): George Washington University:1-8. Available: https://medical-legalpartnership.org/wp-content/uploads/2020/10/ MLP-Literature-Review-2013-2020.pdf (accessed 2021 Jan. 28).

46. Council on Early Childhood; High PC, Klass P. Literacy promotion: an essential component of primary care pediatric practice. Pediatrics 2014;134:404-9.

47. High PC, LaGasse L, Becker S, et al. Literacy promotion in primary care pediatrics: can we make a difference? Pediatrics 2000;105:927-34.

48. Donovan NJ, Blazer D. Social isolation and loneliness in older adults: review and commentary of a National Academies report. Am J Geriatr Psychiatry 2020; 28:1233-44.

49. National Academies of Sciences, Engineering, and Medicine; Division of Behavioral and Social Sciences and Education; Health and Medicine Division, et al. Social Isolation and loneliness in older adults: opportunities for the health care system. Washington (DC): The National Academies Press (US); 2020.

50. Veazie S, Gilbert J, Winchell K, et al. Addressing social isolation to improve the health of older adults: a rapid review. Report No. 19-EHC009-EF. Rockville (MD): Agency for Healthcare Research and Quality (US); 2019:1-59. Available: https:// www.ncbi.nlm.nih.gov/sites/books/NBK537909/pdf/Bookshelf_NBK537909.pdf (accessed 2021 Jan. 28).

51. Pinto AD, Hassen N, Craig-Neil A. Employment interventions in health settings: a systematic review and synthesis. Ann Fam Med 2018;16:447-60.

52. Aubry $\mathrm{T}$, Bloch $\mathrm{G}$, Brcic V, et al. Effectiveness of permanent supportive housing and income assistance interventions for homeless individuals in high-income countries: a systematic review. Lancet Public Health 2020;5:e342-60.

53. Solomon EM, Wing $\mathrm{H}$, Steiner JF, et al. Impact of transportation interventions on health care outcomes: a systematic review. Med Care 2020;58:384-91.

54. Beck AF, Henize AW, Kahn RS, et al. Forging a pediatric primary care-community partnership to support food-insecure families. Pediatrics 2014;134:e564-71.

55. Tarasuk V, Vogt J. Household food insecurity in Ontario. Can J Public Health 2009;100:184-8.
56. De Marchis EH, Torres JM, Benesch T, et al. Interventions addressing food insecurity in health care settings: a systematic review. Ann Fam Med 2019;17: 436-47.

57. Henize AW, Beck AF, Klein MD, et al. A road map to address the social determinants of health through community collaboration. Pediatrics 2015;136: e993-1001.

58. Tsega M, Lewis C, McCarthy D, et al. Review of evidence on the health care impacts of interventions to address the social determinants of health. New York: The Commonwealth Fund; 2019. Available: https://www.commonwealthfund. org/sites/default/files/2019-07/COMBINED_ROI_EVIDENCE_REVIEW_7.15.19.pdf (accessed 2021 Jan. 28).

59. Gunderson JM, Wieland ML, Quirindongo-Cedeno O, et al. Community health workers as an extension of care coordination in primary care: a communitybased cosupervisory model. J Ambul Care Manage 2018;41:333-40.

60. Fisher B. Community development through health gain and service change: Do it now! London J Prim Care (Abingdon) 2014;6:154-8.

61. Raza D, Brown C, Pinto AD. Supporting patients to shape social determinants of health through democratic engagement. Can Fam Physician 2020;66:639-41.

62. Fagnan LJ. Moving upstream: health extension and primary care. J Am Board Fam Med 2017;30:10-2

63. Browne AJ, Varcoe CM, Wong ST, et al. Closing the health equity gap: evidencebased strategies for primary health care organizations. Int J Equity Health 2012;11:59.

64. Browne AJ, Varcoe C, Ford-Gilboe M, et al. Disruption as opportunity: impacts of an organizational health equity intervention in primary care clinics. Int $J$ Equity Health 2018;17:154.

65. Ford-Gilboe M, Wathen CN, Varcoe C, et al. Annette J Browne For The Equip Research Program. How equity-oriented health care affects health: Key mechanisms and implications for primary health care practice and policy. Milbank $Q$ 2018;96:635-71.

66. San'yas Indigenous Cultural Safety Training [home page]. Vancouver: Provincial Health Services Authority. Available: www.sanyas.ca/home (accessed 2021 Jan. 28).

67. Reconciling relationships. Toronto: Centre for Urban Health Solutions (C-UHS) Available: www.welllivinghouse.com/what-we-do/projects/reconciling -relationships/ (accessed 2021 Jan. 28).

68. Bloch G, Rozmovits L, Giambrone B. Barriers to primary care responsiveness to poverty as a risk factor for health. BMC Fam Pract 2011;12:62.

69. Kung A, Cheung T, Knox M, et al. Capacity to address social needs affects primary care clinician burnout. Ann Fam Med 2019;17:487-94.

70. De Marchis E, Knox M, Hessler D, et al. Physician burnout and higher clinic capacity to address patients' social needs. J Am Board Fam Med 2019;32:69-78.

71. Pantell MS, De Marchis E, Bueno A, et al. Practice capacity to address patients social needs and physician satisfaction and perceived quality of care. Ann Fam Med 2019;17:42-5.

72. Maani N, Galea S. The role of physicians in addressing social determinants of health. JAMA 2020;323:1551-2.

73. Mackenzie M, Skivington K, Fergie G. "The state They're in": unpicking fantasy paradigms of health improvement interventions as tools for addressing health inequalities. Soc Sci Med 2020;256:113047.
Competing interests: Gary Bloch has received research funding from the College of Family Physicians of Canada and the Wellesley Institute, and speaker fees from academic family medicine departments, the College of Family Physicians of Canada, provincial Colleges of Family Physicians and the Japan Health Promoting Hospitals Network, outside the submitted work. He is a member of the steering committee of Defend Disability. Linda Rozmovits is an independent consultant who was paid through research funding to participate in the submitted work.

This article has been peer reviewed.

Affiliations: Department of Family and Community Medicine (Bloch), University of Toronto; Department of Family and Community Medicine (Bloch), St. Michael's Hospital; Inner City Health Associates (Bloch); Independent qualitative health research consultant (Rozmovits), Toronto, Ont.

Contributors: Gary Bloch led the conception of the work. Both authors participated in the design of the literature review, the review and analysis of the literature, and the drafting, editing and finalizing of the manuscript. Both authors agree to be accountable for all aspects of the work.

Funding: The development of this article was supported by funding from the AMS Foundation, St. Michael's Hospital Department of Family and Community Medicine, The University of Toronto Department of Family and Community Medicine and the Health Commons Solutions Lab.

Content licence: This is an Open Access article distributed in accordance with the terms of the Creative Commons Attribution (CC BY-NC-ND 4.0) licence, which permits use, distribution and reproduction in any medium, provided that the original publication is properly cited, the use is noncommercial (i.e., research or educational use), and no modifications or adaptations are made. See: https://creativecommons.org/licenses/ by-nc-nd/4.0/

Correspondence to: Gary Bloch, gary.bloch@utoronto.ca 